\title{
Seals as collectors of oceanographic data in the coastal zone
}

\author{
Del Villar-Guerra, Diego; Cronin, Michelle; Dabrowski, Tomasz; Bartlett, Darius
}

Published in:

Estuarine, Coastal and Shelf Science

Link to article, DOI:

10.1016/j.ecss.2012.09.010

Publication date:

2012

Link back to DTU Orbit

Citation (APA):

Del Villar-Guerra, D., Cronin, M., Dabrowski, T., \& Bartlett, D. (2012). Seals as collectors of oceanographic data in the coastal zone. Estuarine, Coastal and Shelf Science, 115, 272-281.

https://doi.org/10.1016/j.ecss.2012.09.010

\section{General rights}

Copyright and moral rights for the publications made accessible in the public portal are retained by the authors and/or other copyright owners and it is a condition of accessing publications that users recognise and abide by the legal requirements associated with these rights.

- Users may download and print one copy of any publication from the public portal for the purpose of private study or research.

- You may not further distribute the material or use it for any profit-making activity or commercial gain

- You may freely distribute the URL identifying the publication in the public portal 
Estuarine, Coastal and Shelf Science

http://dx.doi.org/10.1016/i.ecss.2012.09.010

Copyright (c) 2012 Elsevier B.V. All rights reserved.

DTU Aqua

Institut for Akvatiske Ressourcer

\title{
Seals as collectors of oceanographic data in the coastal zone
}

\author{
Diego del Villar-Guerra ${ }^{1}$, Michelle Cronin ${ }^{2}$, Tomasz Dabrowski ${ }^{3}$ \& Darius Bartlett ${ }^{4}$ \\ ${ }^{1}$ National Institute of Aquatic Resources, Technical University of Denmark, Vejlsøvej 39, 8600 Silkeborg, \\ Denmark. Corresponding author: E-mail: ddvi@aqua.dtu.dk \\ ${ }^{2}$ Coastal and Marine Research Centre, ERI, University College Cork, Ireland \\ ${ }^{3}$ Marine Institute, Oranmore, Galway, Ireland \\ ${ }^{4}$ Department of Geography, University College Cork, Ireland
}

\begin{abstract}
:
Understanding spatial and temporal variation in water temperatures in the coastal zone is generally limited as conventional monitoring platforms often prove problematic in these areas e.g. shallow depths limit access by research vessels, and issues of accuracy and resolution can affect the use of remotely sensed sea surface temperature data. As a result most currently available data on sea temperature are from offshore waters while coastal areas have remained relatively unexplored. Water temperature is an important parameter to study in these coastal waters, considering its impact and influence on the timing and frequency of harmful algal blooms and their associated impacts on aquaculture. It is a significant factor in the timing of the Spring bloom and primary productivity, with consequent influences on the entire marine food web. Advances in bio-logging technologies in recent years have provided opportunities for sensor deployment on a variety of marine animals, including marine mammals, sea birds, fish and turtles, to gather data from inaccessible areas. In this study, we explored the use of telemetry-derived data from instrumented seals in Kenmare Bay in southwest Irish waters to ascertain if seals can be used as sampling platforms in oceanographic studies in the coastal zone and to examine fine scale changes in water temperatures. High spatial and temporal measurements allowed the characterisation of the water dynamics in the estuarine area by the identification of processes such as thermal stratification, up/downwellings and the onset of the thermocline, and provide unique insights into the marine environment in and around the bay, where no previous oceanographic studies have been conducted. Strong correlation between the seal-derived temperature data and in-situ temperature recorders and modelled data validates the use of seals as oceanographic platforms on different spatial scales.
\end{abstract}

Keywords: seals; oceanographic platforms; oceanic models; thermocline; Irish coastal; shelf waters

*Corresponding author: ddvi@aqua.dtu.dk

Article first published online: 10 Dec 2012

Please note that this is an author-produced PostPrint of the final peer-review corrected article accepted for publication. The definitive publisher-authenticated version can be accesses here:

http://dx.doi.org/10.1016/i.ecss.2012.09.010

Page $\mathbf{1}$ of $\mathbf{2 0}$ 


\section{Introduction:}

Bio-logging studies on marine mammals have traditionally been undertaken either to examine behaviour of the animals (e.g. Mc Connell et al., 1999; Block et al., 2003; Biuw et al., 2007) or to use the animals as sensors to collect data to advance our understanding of the physical structure of the oceans, especially by accessing areas of the water column or seabed not easily reached by other means (e.g. Campagna et al., 2000; Boehlert et al., 2001; Costa et al., 2007; Boehme et al., 2008; Charrassin et al., 2008). More recently, advances in sampling and data retrieval devices have made it possible to combine both types of investigation, allowing a synergy between biological and oceanographic studies (e.g. Fedak 2002; Lydersen et al., 2004).

The present study explores the use of telemetry derived data from instrumented seals (harbour and grey seals) in Irish waters to ascertain if they can be used as sampling platforms in oceanographic studies, and to examine fine scale changes in water temperatures in southwest Ireland. To effectively assess the feasibility of using seals as oceanographic platforms it has to be ensured that the temperature values recorded by tags on individual animals truly reflect thermal properties of the studied water masses, rather than differences in the animal's diving behaviour or tag's performance. Seals diving behaviour is therefore a principal component to consider in oceanography studies using instrumented animals. As a diving seal moves irregularly both in time and space, the sensors attached to the animal do not sample in regular patterns, thus it is a real challenge to determine whether an observed change in the water column is spatial or temporal.

The study area comprises an embayment in southwest Ireland, Kenmare Bay, Co. Kerry. Average sea surface temperatures for coastal waters to the west and south of Ireland range from $8-10^{\circ} \mathrm{C}$ in Winter to $14-17^{\circ} \mathrm{C}$ in Summer and tend to be several degrees higher in comparison with the Irish Sea. Those differences are related to the warm Atlantic water on the western Irish Shelf (Lee \& Ramster, 1981; Elliott, 1991). In Winter Irish coastal and shelf waters are vertically well mixed with little differences in the surface-to-bottom distribution of temperature within the water column. As the water column stratifies in summer, a surface-to-bottom temperature difference of up to $6^{\circ} \mathrm{C}$ is typical of waters along the Atlantic Shelf and Celtic Sea (Cooper, 1967; Raine \& McMahon, 1998). 
Southwest coastal waters are characterized by episodic occurrence of coastal upwelling (Edwards et al., 1996), which is primarily wind-driven but can also occur as a result of the bottom topography (O’Boyle \& Silke, 2010). Wind-driven upwelling observed around the southwest coast of Ireland is often associated with elevated biomass levels and changes in phytoplankton composition (Raine et al., 1990a, b; 1993c; 2010; O’Boyle \& Silke, 2010). Such episodes are highly variable in periodicity and magnitude. During periods of relaxation of upwelling, the water surface of this area stabilizes, and is very similar to that of the stratified Atlantic Shelf (Edwards et al., 1996). Such events have a profound effect on the ecology of these areas (O'Boyle \& Silke, 2010).

Understanding spatial and temporal variation in water temperatures in the coastal zone is generally limited, as conventional monitoring platforms prove problematic in these areas e.g. shallow depths limit access by research vessels, and there are issues of accuracy and resolution with remotely sensed sea surface temperature data in the coastal zone (Malthus et al., 2005; Hedger et al., 2007). Although near shore boys and pier based measurements sites contribute to understanding near coastal processes these gauges are usually rather sparse, and restricted to certain water bodies (Dwyer, 2009).

As a result most currently available data on temperature in Irish waters are from further offshore, while coastal areas have remained relatively unexplored. Water temperature is an important parameter to study in these coastal waters, considering its impact and influence on the timing and frequency of harmful algal blooms and their associated impacts on aquaculture. It is a significant factor in the timing of the spring bloom and primary productivity, with consequent influences on the entire marine food web.

Due to a high degree of site-fidelity and coastal foraging Irelands' two seal species, the grey seal (Halichoerus grypus) and harbour seal (Phoca vitulina vitulina) are ideal for the study of coastal/estuarine water masses by means of bio-logging. Seals have established themselves at terrestrial colonies along the coastline of Ireland (Ó Cadhla et al., 2005; Cronin et al., 2007) where they come ashore to breed and moult, thus being available for capture and sensor deployment. Both species of seal have different foraging ranges and distributions: harbour seals generally make 
small-scale local foraging trips, whilst grey seals range over much wider areas (Cronin et al., 2008), providing platforms for monitoring water temperature at two different spatial scales.

The present study assesses the feasibility of using seals as platforms for monitoring water temperature in waters off the southwest and west coasts of Ireland on two spatial scales by comparing the seal-acquired data to in situ temperature recordings in a bay in southwest Ireland, and to predicted temperatures of water masses off the entire west coast of Ireland derived from a global ocean model (Olbert et al. 2011). Detailed examination of the thermal characteristics of water masses within Kenmare Bay, in southwest Ireland, was conducted and temporal variation in the occurrence of the thermocline during the study period examined using the data acquired by the seal-deployed sensors. Some oceanographic studies have previously been conducted in Bantry Bay, immediately to the south of Kenmare Bay (Raine et al., 1990a,b; 1993 a,b,c; Edwards et al., 1996; Mc Mahon et al., 1997; Gribble et al., 2007). However, this research constitutes the first attempt to study seasonal water temperature change in Kenmare Bay.

\section{Material and methods}

Between 2006 and 2009, 8 grey seals (Halichoerus grypus) and 17 harbour seals (Phoca vitulina vitulina) on the south-west coast of Ireland were tagged with GSM/GPS tags with temperature sensors (Sea Mammal Research Unit, SMRU, Scotland). For details of capture and deployment of tags on the harbour seals in 2006 and 2007 see Cronin \& McConnell (2008). Capture of grey seals and deployment of 8 GPS/GSM tags was carried out at haul-out sites on An Trá Bán on the Great Blasket Island, Co. Kerry $\left(52.08^{\circ} \mathrm{N}-10.62^{\circ} \mathrm{W}\right)$ in February 2009. Grey seals use the beach as a moult site between December-May each year. Tags were glued to the seals fur behind the head, tagging therefore took place post-moult to ensure a maximum period of tag attachment. The site was chosen because of its national importance and its location in southwest Ireland where previous tagging efforts on harbour seals had been conducted (Cronin \& McConnell, 2008; Cronin et al., 2007). Temperature data collected by the tags during the period of February to December 2009 were compared to temperature data provided by ocean models of the western Irish shelf (Olbert et al., 2011). The temperature data collected by the tags deployed on the harbour seals during the 
months of April to August for the years 2006 and 2007 were examined for temporal and spatial variation in water temperatures within the outer regions of Kenmare Bay, Co. Kerry $\left(51.78^{\circ} \mathrm{N}\right.$ $\left.9.94^{\circ} \mathrm{W}\right)$ (Fig 1.)

\section{Tag hardware and data acquisition}

The GSM/GPS tags attached to the seals combine the advantages of GPS positioning with mobile telephone technologies for efficient data transmission. They also incorporated a hybrid fast acquisition GPS system Fastloc (Wildtrack Telemetry Systems, Leeds) (see Rutz and Hayes, 2009), providing up to 12 at-sea positions per day. The tag also processes data from wet/dry, pressure and temperature sensors, to form detailed individual dive and haul-out records along with temperature profiles.

The thermal sensor in the tag recorded temperature values in Celsius with a resolution of $0.01^{\circ} \mathrm{C}$. The ranges of readings were $5^{\circ} \mathrm{C}$ to $35.95^{\circ} \mathrm{C}$, in increments of $0.01^{\circ} \mathrm{C}$. The temperature sensor was triggered if a dive was one of the two deepest dives in each two hour period. Temperature data were recorded at one-second intervals on the ascent. Filtering and compression were performed by conventional broken-stick method (Fedak et al., 2002), producing 12 temperature-depth pairs. The GPS-locations, dive, haul-out records and temperature data were stored on board the tag. Every 6 hours the tag attempted to register with a local GSM mobile phone service provider. Once GSM coverage was obtained, normally when a seal came near shore, the entire set of data records stored in memory was relayed via the mobile phone system to the receiving database (McConnell et al., 2004).

\section{Variation in temperature data between individual tags}

Kernel analysis (Silverman 1986) was used in order to select high-density sampled areas, where there is greater probability of finding different individual seals sampling within the same water body, across the same period of time. Tests were conducted to determine if there were differences in the data collected by different seals in the same area (clusters), within the same 
period of time, to examine if there was variability in thermal sensor sensitivities and/or tag performance. Clusters were defined as those 95\% Kernel areas where two or more individuals were recording temperature data at the same time. A Mann-Whitney $U$ test was used to determine variation in the temperature data between two individuals in the same cluster, and Kruskal-Wallis test when the comparison involved more than two individuals. Temperature records were examined from $5 \mathrm{~m}$ depth to $40-60 \mathrm{~m}$. Subsequent analyses were only carried out on data from tags that did not differ significantly from other tags in the same cluster, indicating reliable tag performance.

\section{Thermal variations in Kenmare Bay and thermocline identification}

Temperature data collected by harbour seals during the months April to August for two consecutive years, 2006 and 2007, were examined. During this time, seals spent over $90 \%$ of the deployment period in lower Kenmare Bay approximating an area of $50 \mathrm{~km}^{2}$ (Fig. 1).

The thermal variations in Kenmare Bay were mapped using Ocean Data View v.4 (ODV) software (Schlitzer, 2009) and DIVA gridding interpolation was applied (Data-Interpolating Variational Analysis, SeaDataNet-ULg 2009). To identify the variation in the thermocline in the waters of Kenmare Bay, across the tagging period, we used threshold methods (Thomson and Fine, 2003) using a depth-to-depth temperature difference (e.g. Defant, 1961; Wijffels et al., 1994; Kara et al., $2000,2001)$. The derivative of the temperature-depth function was calculated at each pair of consecutive depth points through each temperature-depth profile, for all the profiles as follows:

$y=\Delta T=\left|T_{z b}-T_{z a}\right|$

Where $T_{z b}$ is the temperature at depth $z b$ and $T_{z a}$ the temperature at depth $z a, z a$ and $z b$ ranging from a minimum of $5 \mathrm{~m}$ to a maximum of $200 \mathrm{~m}$. The maximum rate of temperature change over a small depth increment equated with those points where the minimum slope, Minslope, of the temperature-depth profile was observed, and this was considered to indicate the presence of the hypothetical existence of thermocline for each profile. 
Minslope $=\max \left(\frac{\Delta y}{z b-z a}\right)$

The average of temperatures $T_{z a}$ and $T_{z b}$ where the minimum slope was observed constituted the $T_{\text {Minslope }}$. To study thermal variations through all the temperature-depth profiles in a monthly basis the simple moving average method (SMA) was performed to the $T_{\text {Minslope }}$. It was assumed that this is where the relevant information in terms of the study of the thermocline is presented. The moving average for a specific time was computed as follows:

SMA $=\frac{T_{\text {Min slope }(t)}+T_{\text {Min slope }(t-1)}+\cdots+T_{\text {Min slope }(t-(n-1))}}{n}$

$\mathrm{SMA}_{(\mathrm{t})}=\mathrm{SMA}_{(\mathrm{t}-1)}-\frac{\mathrm{T}_{\text {Minslope (t-n) }}+\mathrm{T}_{\text {Minslope (t) }}}{\mathrm{n}}$

Where $T_{\text {Minslope ( } t)}$ represents the value of Temperature of minimum slope at particular time, $t$ and $n$ is the number of observations.

The data were examined for evidence of up/down-welling, stratification and temporal variation in the thermocline during the study period in the Kenmare Bay between the months April and August for two consecutive years (2006 and 2007). A Kruskal-Wallis test was performed to examine the differences on the thermocline across the study period.

\section{Tag derived temperature data validation}

Validation of the tag derived temperature data was carried out at two spatial scales. Firstly temperature data from a seal tagged in the Kenmare Bay that spent a significant proportion of time in Bantry Bay (approximately $20 \mathrm{~km}$ south of Kenmare Bay) was compared with temperature records provided by internal logging temperature sensors (Tidbits) deployed by the Irish Marine Institute in Bantry Bay. The Tidbit sensor is a completely sealed underwater temperature logger with optic communication, providing hourly temperature data at several depths (1m, $8 \mathrm{~m}$ and $12 \mathrm{~m})$ 
in the water column (Onset ${ }^{\circledR}$ Hobo $^{\circledR}$, Data loggers). Tag-derived temperature data sampled from points within the $100 \mathrm{~m}$ buffer surrounding the station were selected for comparison and a nonparametric linear regression of tag and Tidbit derived temperature data was conducted. A total of 287 seal-derived temperature profiles were compared to Tidbit data.

Secondly, temperature data from 8 tags deployed on grey seals, which have a much wider at-sea distribution than harbour seals (Fig. 1), approximating $60000 \mathrm{~km}^{2}$ were compared to temperatures predicted by the MPI-OM global ocean model developed at the Max-Planck-Institute for Meteorology, Hamburg, Germany. Technical details of the MPI-OM model and the model parameterization can be found in Marsland et al. (2003).

This model has been validated for Irish coastal waters (Olbert et al., 2011) and had been previously used in the study of regional climate changes in the Irish Sea (Olbert et al., 2012). The model produced vertical distributions of water temperatures off the west coast of Ireland (see Olbert et al. 2011) facilitating comparisons to the seal derived temperature data. The model predictions were compared to the temperature data recorded by the 8 seal deployed sensors for the same geographical area (see Fig. 1) $\left(52-57.9^{\circ} \mathrm{N}\right.$ and $\left.6.2-11.2^{\circ} \mathrm{W}\right)$ between February 2009 and December 2009 using a non-parametric linear regression. Mann-Whitney $U$ tests were used to determine differences between the two data sets when comparisons of temperature at specific depths were made (at 10-30m intervals between 5-205m).

\section{Results}

Over 20,000 temperature-depth profiles of the water column were recorded by the tags deployed on the 25 seals during the study period, totalling over 0.25 million separate temperature readings. A total of 10,904 temperature/depth profiles were provided by 17 harbour seals tagged during April 2006-May 2008 over 1233 days. During this period these tags recorded an average of 2.64 temperature/depth profiles per day. A total of 11,556 temperature/depth profiles were recorded by 8 grey seals tagged during February to December 2009 over 1,575 days, collecting an average of 7.19 temperature/depth profiles per day. 


\section{Tag validation}

Cluster analysis revealed that 19 out of 25 tags showed no significant differences in the data collected by seals in the same clusters within the same period of time and were considered for further analysis. In the cases where significant differences were found between readings taken by tags attached to the seals within the same cluster these data were not used for subsequent analysis of temperature distribution.

\section{Temperature distributions in Kenmare Bay}

The median sea-surface temperature (0-10 dbars) increased from $10.67^{\circ} \mathrm{C} \pm 1.08$ in April 2006 to over $18^{\circ} \mathrm{C}$ by August 2006 in certain areas of the outer Kenmare Bay. Cold water from $9.0-9.5^{\circ} \mathrm{C}$ was observed in April at a depth of $25 \mathrm{dbars}$ and in May at $40 \mathrm{dbars}$. The decrease in depth of the $9-9.5^{\circ} \mathrm{C}$ isotherm suggested a progressive solar heating of the water column. Coinciding with this warming, a continuous stratification process was observed during June, July and August 2006 (Fig. 2).

The visual inspection of the temperature-depth charts suggested evidence of periodic upwelling in the area of Kenmare Bay for the month of June 2006 (Fig. 3). Isotherms of $9^{\circ} \mathrm{C}$ and $10^{\circ} \mathrm{C}$ were found at the surface level (0-10 dbars) within warmer coastal surface waters, with temperatures ranging from $13^{\circ} \mathrm{C}$ to $16^{\circ} \mathrm{C}$. This upwelling event was followed by the subsequent relaxation (downwelling) where the $9-10^{\circ} \mathrm{C}$ isotherms had disappeared in the month of July and August. Transient local upwellings were also identified in June 2007 associated with the entrance of deep offshore water masses into the study area. The cool dense water rose, displacing the $11^{\circ} \mathrm{C}$ isotherm at the surface in extended areas of outer regions of Kenmare Bay (Fig. 4). The change in the location of the $11^{\circ} \mathrm{C}$ isotherm throughout the months of April to August 2007 is evidence of local upwelling and downwelling in the area of Kenmare Bay.

Temperatures at the point where the vertical gradient in temperature was strongest (hypothetical thermocline) were significantly different during April 2006 to August $2006(p<0.0001)$ in the study 
area within Kenmare Bay, and the same pattern was evident between April and August 2007. Changes in the temperature observed in the thermocline suggest a warming process from April onwards to August affecting the complete water column. Average temperatures of recorded thermocline rose from $10.17^{\circ} \mathrm{C} \pm 0.8$ to a maximum of $15.80^{\circ} \mathrm{C} \pm 1.07$ by the middle of August 2006 . In 2007 the thermocline temperature increased from a minimum of $11.31^{\circ} \mathrm{C}$ in April to a maximum of $13.17^{\circ} \mathrm{C}$ by the end of August and the sea surface average temperatures increased from $12^{\circ} \mathrm{C}$ in April to a maximum of $18^{\circ} \mathrm{C}$ in August.

\section{Tag performance against other sensors}

The seal-derived temperature data and the Tidbit data were compared at depths of $1 \mathrm{~m}, 8 \mathrm{~m}$ and $12 \mathrm{~m}$ for the month of November 2006. Non-parametric methods (Spearman's rho) applied to the data showed significant correlations at all three depths $(p<0.01)$, confirming that the instrumentation deployed on the seals was recording similar temperature records as those collected by an independent sensor in the same area and period of time.

There was a significant correlation $(p<0.01)$ between temperatures predicted by the MPI-OM global ocean model and the temperatures recorded by the tags deployed on the seals between the months of February to December 2009 for most months apart from April and December (Table 1; Fig.5). A Mann-Whitney Test showed no significant differences between the two data sets when comparisons of temperature at different depths were made $(P>0.05)$. The differences encountered between model predictions and field data are likely to result from averaging over an extensive area, and non-uniform distribution of seals throughout the region.

\section{Discussion}

The study is the first attempt to examine water temperature changes in Kenmare Bay, and allowed the identification of the main temperature changes and structures within the water body including signs of stratification associated with a warming process, up/down welling episodes, identification of the thermocline, and the study of the temperature variability through the years 2006 and 2007. 
The unique data set, with a high spatial and temporal resolution, contains more than 20,000 temperature-depth records and, as confirmed by a search of the online Irish Spatial Data Exchange data base (http://catalogue.isde.ie) (ISDE; 2012), is one of the richest temperature datasets currently available for Irish coastal waters. It thereby provides a comprehensive basis for studying an area that has been poorly investigated to date.

In comparison to the coastal waters further offshore, Irish estuarine waters are still relatively unknown in terms of their structure and environmental functioning. The data and information relating to these environments is rather sparse, and is restricted to a small number of water bodies. Most studies conducted in those waters have focused on the relationships between the episodes of phytoplankton and zooplankton blooms and water column changes, to consolidate the understanding of the ecology of those organisms in the region (e.g. O'Boyle \& Silke, 2010). The temperature data gathered by the tagged seals have been shown sufficient for mapping and analysing thermal structure at different depths, although it is acknowledged that a full interpretation of these water masses cannot be made solely from these data alone (e.g. lack of salinity measurements). Nevertheless, the results obtained in the present study are in line with current understanding of estuarine waters more generally, and provide unique insights to the marine environment in and around Kenmare Bay, where no previous oceanographic studies have been conducted.

The present study characterized the estuarine waters of Kenmare Bay as rapid changeable waters (scales of days) with their own structure, defining those water bodies as partially mixed estuary waters (e.g. O’Boyle \& Silke, 2010). High spatial and temporal measurements used in the study allowed for the characterisation of the water dynamics in the estuarine areas by the identification of processes such as thermal stratification, up/downwellings and the onset of the thermocline. Although evidence for mesoscale upwelling in the Ireland's southwest coastal waters is equivocal (Edwards et al., 1996), the measurements and analyses presented in this study reveal for the first time the existence of transient coastal upwelling in the area of Kenmare Bay. Both up- and downwelling appeared in the bay, over several timescales, during the month of June in two consecutive years, 2006 and 2007. In the adjacent bay, Bantry Bay, such episodes have been associated with 
the prevailing winds at the time, which drive offshore Ekman transport of coastal surface water, with a compensating injection of deeper offshore waters into the bays (Edwards et al., 1996).

In the area of Kenmare Bay, the upwellings were associated with shallow areas in which inlets are predominant, and also with the middle parts of the bay where the topography facilitates the vertical water movements. The area of Sneem harbour was characterized by transient recurrent upwellings associated with the bottom bathymetry of the area as derived from bathymetry elevation models provided by the Admiralty charts of the area (Admiralty Charts and Publications. Sheet Number 2495, 1997). The anticipated future availability of finer-scale bathymetry data, e.g. when the area is surveyed as part of the Irish National Seabed Survey (INSS) will contribute to a better understanding of the local upwellings in the area.

Atlantic atmospheric depressions during June favoured some transport of colder offshore water towards the coast at depth. During July and August south-westerly winds returned, associated with the beginning of the stratification process within outer Kenmare Bay. The duration and intensity of the atmospheric depressions, as well as the gradient of temperatures between the surface and the bottom water masses, facilitated by and in combination with the bathymetry and prevailing local winds, are factors which influence water column dynamics. Data collected by seals, together with the techniques for their analysis as described in this paper, should provide a good methodological foundation for further detailed study of these ocean-atmosphere processes and relationships.

Mapping the temperature distributions of sea surface temperature, did not allow identification of upwelling when the data were averaged into monthly groupings, but these episodes were observed when creating time series at finer, daily timescales. Through experimentation, it was observed that timescales ranging from one day to 10-15 days maximum were optimal for inferring the existence and locations of upwelling in the bay. Although the present research has not included any specific analysis to assess the riverine inputs in the area of Kenmare Bay, more general observation during the research period would indicate that, in general terms, riverine inputs in the area of Kenmare Bay are not significant enough to drive the dynamics of the bay 
themselves. The identified water masses in the area of Sneem harbour had the same thermal structure as those presented in the middle parts of the bay. It could be considered that the interaction of tidal range (2-4 m) and strength of tidal current (See Simpson and Hunter, 1974) allows a thermal stratification in the bay, while the tidal force is sufficiently strong to prevent the river flow from dominating the circulation.

The stratification of the water column observed in Kenmare Bay appears to be largely due to temperature variations, in line with the earlier conclusion of Raine et al. (1990a) that salinity is not as significant as temperature in determining water column structure in Bantry Bay, adjacent to and immediately south of Kenmare Bay (Raine et al., 1990a).

Starting in June and fully developed by August (the onset of the thermocline), the development of thermal stratification through Spring and Summer controls the annual cycle of the plankton (zooplankton and phytoplankton) in temperate waters (Tett and Edwards, 1984).

The present study suggests a likely increase in the primary productivity in June, July and August during 2006 and 2007, coinciding with the upwellings/downwellings and the onset of thermocline in the area. Further studies, using retrospective data on primary productivity e.g. using chlorophyll measurements from satellite imagery as a proxy (if high enough spatial resolution data could be obtained), might help establish the relationships between the timing of the main water changes events and any corresponding primary productivity in the bay during the period of time covered by the study.

The sensitivity of the thermal sensors deployed on the seals (resolution $0.01^{\circ} \mathrm{C}$ ) was adequate to measure water temperature properties in Kenmare Bay as the observed changes in the water column were in the range of $0.5-1^{\circ} \mathrm{C}$. However a shortcoming of the sensor is its inability to record sub-sea-surface geographical locations with any certainty or accuracy, since GPS fixes cannot be obtained while the sensor is submerged, due to the inability of radio signals to travel under water. For the purposes of this research, a straight line between two consecutive GPS-fixed locations recorded at the surface, and the maximum notional speed recorded for the seals while 
submerged, were used to approximate the locations at which the tags deployed on the seals most probably obtained their data measurements. While a pragmatic and effective way of data collection and relay (the data can be accessed in near real time), this methodology introduces uncertainties in the sampling process. The availability of GPS locations therefore determined the number of the underwater geographical locations sampled, and the positional accuracy of the underwater parameters such as thermal properties and depth. In the present study differences ranging up to 3-4 hours were observed between some pairs of consecutive GPS fixes, and during this period of time the seal could have dived in any direction within the bay, and could have travelled over distances of up to a maximum of $10 \mathrm{~km}$ from point of submergence, according to the maximum notional speed determined for these animals. This study sought to assess the possible implications of this complication by using kernel analysis to identify and analyse temperature data in those areas where there was high-to-medium probability of finding a temperature-depth record. It was thought that those areas present high fidelity in relation with the water masses below. No previous studies have adequately addressed the accuracy issues in relation to the locations of temperature readings obtained from tagged animals, possibly because most studies to date deal with large geographical scales and therefore positional accuracy of temperature readings becomes less important e.g. Southern Ocean (Costa et al, 2007). It is recommended that any future analysis using data derived from tagged seals (particularly if assessing thermal properties of water masses on a relatively fine scale e.g. within an estuary/bay, coastal zone) should consider these aspects in greater detail, examining each temperature depth profile individually and giving quality flags according to the criteria described above. Further analysis based on Markov chain methodologies (Collins, 1975) could potentially introduce a more accurate estimation of the animals' behavioural component when calculating underwater locations, and might be a fruitful line for future investigation.

The authors acknowledge the importance of validating the data provided by the instrumented seals, as an essential step in assessing the feasibility of the technique compared to more traditional methods. Significant correlation between the water temperature data collected by the tagged seals and the in situ temperature probe loggers (Tidbits) was found. Multisampling points around the bay (e.g. from seals) capture more water variability than a single point, enabling a 
more comprehensive description of the water circulation within the bay. Autonomous samplers such as instrumented seals, when correctly calibrated and validated, therefore provide better approximations of the main water temperature changes than the information supplied by instruments such as Tidbits alone. Looking beyond the confines of southwest Ireland, temperature data from the continental shelf off the Irish west coast were captured by instrumented grey seals. Analyses of these data were compared with the predictions provided by the oceanic numerical model and significant correlation was found between the two data sets in all months apart from April and December 2009; in these months a small number of records of the seals' temperature/depth data coincided with the same depths for which the model calculated temperatures. Any differences that were observed between model predictions and seal-derived data are likely to result from averaging over an extensive geographical area, and non-uniform distribution of seals throughout the region (Olbert et al., 2011). The strong correlation with the temperature probes (Tidbits) as well as the modelled data validates the use of seals as oceanographic platforms on different spatial scales. Grey seals generally have a larger foraging range than harbour seals (Thompson et al., 1996) and the scale of the study will inform the selection of species for sensor deployment.

The present study proposes that advances in techniques for calibrating and validating data sets obtained from tagged seals may shortly lead to the use of these data as inputs to oceanic models. The incorporation of reliable seal-derived data would also contribute to the improvement of the actual climate monitoring system in Ireland, while the incorporation of fluorometers and salinity sensors within seal-deployed tags will further enhance the potential of using seals as oceanographic platforms, and will open up a new field in oceanographic studies. Advances in data storage/compression and relay are needed in the field of bio-logging for these benefits to be realised, and will possibly allow the establishment of near real-time forecasting routines when combined with the ocean models in the area.

\section{Acknowledgements}


We would like to acknowledge the following for their valuable contributions to the fieldwork elements of the project: David Thompson (National Trust), Paddy Pomeroy, William Patterson, Bernie McConnell (SMRU), Clare Heardman, Declan O Donnell, Oliver O Cadhla, Frank McMahon, Tim O Donoghue and Pascal Dower (NPWS), Mark Jessopp, Mick Mackey, Alan Whittaker (UCC) and Simon Ingram (University of Plymouth). We would like to thank Martin White of NUIG (Ireland) and Jenny Ullgren of NIOZ (Netherlands) for their advice during the analysis of this particular data set. Additional thanks to Clint Blight and Phil Lovell from SMRU (Scotland) for their technical support throughout the project. Thanks to Anders Koed and Kim Aarestrup (DTU-Aqua, Denmark) for facilitating the editing process. The research was funded by the Higher Education Authority under the PRTLI4 funding mechanism. Elements of the research were part funded by a Beaufort Marine Research Award carried out under the Sea Change Strategy and the Strategy for Science Technology and Innovation (2006-2013), with the support of the Marine Institute, funded under the Marine Research Sub-Programme of the National Development Plan 2007-2013. Funding for the telemetry devices was provided by the National Parks \& Wildlife Service. 


\section{References}

Biuw, M., Boehme, L., Guinet, C., Hindell, M., Costa, D., Charrassin, J.-B., Roquet, F., Bailleul, F., Meredith, M., Thorpe, S., Tremblay, Y., McDonald, B., Park, Y.-H., Rintoul, S., Bindoff, N., Goebel, M., Crocker, D., Lovell P., Nicholson, J., Monks, F., and Fedak, M. A., 2007. Variations in behaviour and condition of a southern ocean top predator in relation to in situ oceanographic conditions. Proceedings of the National Academic Science, 104:13705-13710

Block, B.A., Costa, D.P., Boehlert, G.W. and Kocheva, R.E., 2003. Revealing pelagic habitat use: the tagging of Pacific pelagics program, Oceanologica Acta 25 , pp. 255-266

Boehlert, G.W., Costa, D.P., Crocker, D.E., Green, P., O'Brien, T., Levitus, S. and Le Bœuf, J., 2001. Autonomous pinniped environmental samplers: using instrumented animals as oceanographic data collectors. J. Atmos. Ocean. Techn., 18, 1882-1893

Boehme, L., Meredith, M. P., Thorpe, S. E., Biuw, M. and Fedak, M., 2008. The ACC frontal system in the South Atlantic: monitoring using merged Argo and animal-borne sensor data., Journal of Geophysical Research, 113, C09012.

Campagna, C., Rivas, A.L. and Marinn, M.R., 2000. Temperature and depth profiles recorded during dives of elephant seals reflect distinct ocean environments. J. Mar. Syst., 24, 299-312

Charrassin, J.-B., Hindell, M., Rintoul, S. R., Roquet, F., Sokolov, S., Biuw, M., Costa, D., Boehme, L., Lovell, P., Coleman, R., Timmermann, R., Meijer, A., Meredith, M., Park, Y.-H., Bailleul, F., Goebel, M., Tremblay, Y., Bost, C.-A., McMahon, C. R., Field, I. C., Fedak, M. A., and Guinet, C., 2008. Southern Ocean Frontal Structure and Sea-Ice Formation Rates Revealed by Elephant Seals, P. Natl. Acad. Sci. USA, 105, 11634-11639

Collins, L., 1975. An introduction to Markov chain analysis. Inst. Br. Geogr. Study Group in Quantitative Methods, CATMOG No. 1, Geo Abstracts Ltd, Norwich

Cooper, L. H. N., 1967. The physical oceanography of the Celtic Sea. Oceanography. Marine. Biology. Annual Review, 5, 99-110

Costa, D. P., Klinck, J. M., Hofmann, E. E., Dinniman, M. S., Burns, J. M., 2007. Upper ocean variability in west Antarctic Peninsula continental shelf waters as measured using instrumented seals. Deep Sea Research Part II: Topical Studies in Oceanography, Volume 55, Issues 3-4, Dynamics of Plankton, Krill, and Predators in Relation to Environmental Features of the Western Antarctic Peninsula and Related Areas: SO GLOBEC Part II, February 2008, Pages 323-337 
Cronin, M.A., McConnell, B.J., 2008. SMS seal: a new technique to measure haul-out behaviour in marine vertebrates. J Exp Mar Biol Ecol 362:43-48

Cronin, M., Duck, C. and Ó Cadhla, O., 2007. Aerial surveying of grey seal breeding colonies on the Blasket Islands, Co. Kerry, the Inishkea Group, Co. Mayo and the Donegal coast, Ireland, Journal for Nature Conservation Vol: 15 between 1-11

DIVA-Interpolation. 2009. Data-Interpolating Variational Analysis, SeaDataNet-ULg

Defant, A., 1961. Physical Oceanography, Vol. 1. Pergamon, New York, p. 729

Dwyer, N., 2009. Current Status and Required Actions for National Climate Observing Systems, ERC Report 14 Published by: Environmental Protection Agency, Johnstown Castle Co. Wexford, Ireland No. of pages: 68

Edwards, A., Jones, K., Graham, J. M., 1996. Transient coastal upwelling and water circulation in Bantry Bay, a ria on the southwest coast of Ireland. Estuar. Coast. Shelf Sci., 42, 213-230.

Elliott, S. A. J., 1991. Monthly distributions of surface to bottom temperatures in the northwest European shelf sea. Cont. Shelf Res., 11, 453-466

Fedak, M., Lovell, P., McConnell, B., and Hunter, C., 2002. Overcoming the Constraints of Long Range Radio Telemetry from Animals: Getting More Useful Data from Smaller Packages. INTEG. AND COMP. BIOL., $42,3-10$

Fedak, M., Lovell, P., McConnell, B., and Hunter, C., 2002. Overcoming the Constraints of Long Range Radio Telemetry from Animals: Getting More Useful Data from Smaller Packages. INTEG. AND COMP. BIOL., $42,3-10$

Gribble, K. E., Nolan, G. and Anderson, D. M., 2007. Biodiversity, biogeography, and potential trophic impact of Protoperidinium spp. (Dinophyceae) off the southwestern coast of Ireland. J. Plankton Res., 29, 931-947.

Hedger, R. D., Malthus, T. J., Folkard, A. M., Atkinson, P. M., 2007. Spatial dynamics of estuarine water surface temperature from airborne remote sensing, Estuarine, Coastal and Shelf Science, Volume 71, Issues 3-4, Pages 608-615

Irish Spatial Data Exchange data base (ISDE; 2012): http://catalogue.isde.ie

Kara, A. B., Rochford, P. A. and Hurlburt, H. E., 2000. An optimal definition for ocean mixed layer depth. J. Geophys. Res. C, 105, 16803-16821.

Kara, A. B., Rochford, P. A. and Hurlburt, H. E., 2001. Naval Research Laboratory Mixed Layer Depth (NMLD) Climatologies. 7330-01-9995. Naval Research Laboratory, Washington, DC.

Lee, A. J. and Ramster, J. W., 1981. Atlas of the Seas around the British Isles. Ministry of Agriculture Fisheries and Food, Directorate of Fisheries Research. 
Lydersen, C., Nøst, O.A., Kovacs, K.M. and Fedak, M.A., 2004. Temperature data from Norwegian and Russian waters of the northern Barents Sea collected by free-living ringed seals. J. Mar. Syst.

Malthus, T.J., Mumby, P.J., 2003. Remote sensing of the coastal zone: an overview and priorities for future research. International Journal of Remote Sensing. Volume 24, Number 13, 2003 , pp. 2805-2815(11)

Marsland, S.J., Haak, H., Jungclaus, J.H., Latif, M., Roske, F., 2003. The Max-Planck-Institute global ocean sea/ice model with orthogonal curvilinear coordinates. Ocean Modelling 5, 91-127.

McConnell, B. J., Fedak, M. A. , Lovell, P., Hammond, S., 1999. Movements and foraging areas of grey seals in the North Sea. Journal of Applied Ecology 36:1-19.

McMahon, T. and Silke J., 1997. Algal blooms and algal toxicity in Irish Coastal Waters. In Wilson, J. G. (ed.), Eutrophication in Irish Waters. Royal Irish Academy, Dublin, Ireland.

Meunier, T., Rossi, V., Morel, Y, Carton, X. 2010. Influence of bottom topography on an upwelling current: Generation of long trapped filaments, Ocean Modelling, Volume 35, Issue 4, Pages 277-303.

Ó Cadhla O, Strong, D. and O'Donnell, G., 2005. Grey seal population status in the Slyne Head SAC/SPA and Hen Island, Co. Galway as determined from breeding ground surveys in 2004. Report to the Department of the Environment, Heritage and Local Government. 7pp.

O'Boyle, S. \& Silke, J., 2010. A review of phytoplankton ecology in estuarine and coastal waters around Ireland. Journal of Plankton Research. Vol: 32, $\mathrm{N}^{\circ}: 1$, pp. 99-118

Olbert, A.I., Dabrowski, T., Nash, S., Hartnett, M., 2012. Regional modelling of the 21st century climate changes in the Irish Sea. Continental Shelf Research, 41: 48-60.

Olbert, A., Hartnett, M., Dabrowski, T., Mikolajewicz, U., 2011. Long-term inter-annual variability of a cyclonic gyre in the western Irish Sea, Continental Shelf Research, Volume 31, Issue 13, Pages 13431356, ISSN 0278-4343, 10.1016/j.csr.2011.05.010.

Onset $^{\circledR}$ Hobo $^{\circledR}$, Data loggers.TidBit v2 Water Temperature Data Logger - UTBI-001. Retrieved 25/08/2011,from http://www.onsetcomp.com/products/data-loggers/utbi-001ref

Raine, R. and McMahon, T., 1998. Physical dynamics on the continental shelf off southwestern Ireland and their influence on coastal phytoplankton blooms. Cont. Shelf Res., 18, 883-914.

Raine, R., McMahon, T. and Roden, C. M., 1993a. A review of the summer phytoplankton distribution in Irish coastal waters, a biogeography related to physical oceanography. Biogeography of Ireland, past, present and future. In Costello, M. J. and Kelly, K. S. (eds), Occas. Pub. Irish Biogeogr. Soc., Vol. 2. pp. 99-111.

Raine, R., Joyce B., Richard J., 1993b. The development of an exceptional bloom of the dinoflagellate Gyrodinium aureolum on the southwest Irish coast. ICES J. Mar. Sci., 50, 461-469. 
Raine, R., Joyce, B., Patching, J. W., 1993c. Upwelling and the phytoplankton ecology of southwest Irish coastal waters. ICES Biol. Oceanogr. Comm., C.M. L,18.

Raine, R., O'Mahony, J., McMahon, T., 1990a. Hydrography and phytoplankton of waters off south-west Ireland. Estuar. Coast. Shelf Sci., 30, 579-592.

Raine, R., McMahon, T., O'Mahony, J., 1990b. Water Circulation and phytoplankton populations in two estuaries on the west coast of Ireland. In Chambers, P. L. and Chambers, C. M. Estuarine Ecotoxicology. JAPAGA, Wicklow, 19-28.

Raine, R., McDermott, G., Silke, J., Lyons, K., Nolan, G., Cusack, C., 2010. A simple short range model for the prediction of harmful algal events in the bays of southwestern Ireland, Journal of Marine Systems 83(3-4), 150-157.

Rutz, C. and Hays, G.C., 2009. New frontiers in biologging science. Biological Letters. 5, 289-292.

Schlitzer, R., 2009. Ocean Data View, http://odv.awi.de.

Sea Mammal Research Unit, 2008. GPS Phone Tags. Retrieved 25/08/2011, from http://www.smru.stand.ac.uk/Instrumentation/pageset.aspx?psr=287.

Simpson, J.H., and Hunter, J.R., 1974. Fronts in the Irish Sea. Nature, 250, 404-406.

Silverman, B. W., 1986. Density Estimation for Statistics and Data Analysis, Monographs on Statistics and Applied Probability, Chapman and Hall, London, UK.

Tett, P. and Edwards, A., 1984. Mixing and plankton, an interdisciplinary theme in oceanography. Oceanogr. Mar. Biol. Annu. Rev., 22, 99-123.

Thompson, P., McConnell, B., Tollit, D., Mackay, A., Hunter, C. and Racey, P.,1996. Comparative distribution, movements and diet of harbour and grey seals from the Moray Firth N.E. Scotland. Journal of Applied Ecology, 33, 1572-1584.

Thomson, R. E. and Fine, I. V., 2003. Estimating mixed layer depth from oceanic profile data. J. Atmos. Ocean. Technol., 20, 319-329.

Wijffels, S., Firing, E. and Bryden, H., 1994. Direct observations of the Ekman balance at $108 \mathrm{~N}$ in the Pacific. J. Physical Oceanography. 24, 1666-1679. 

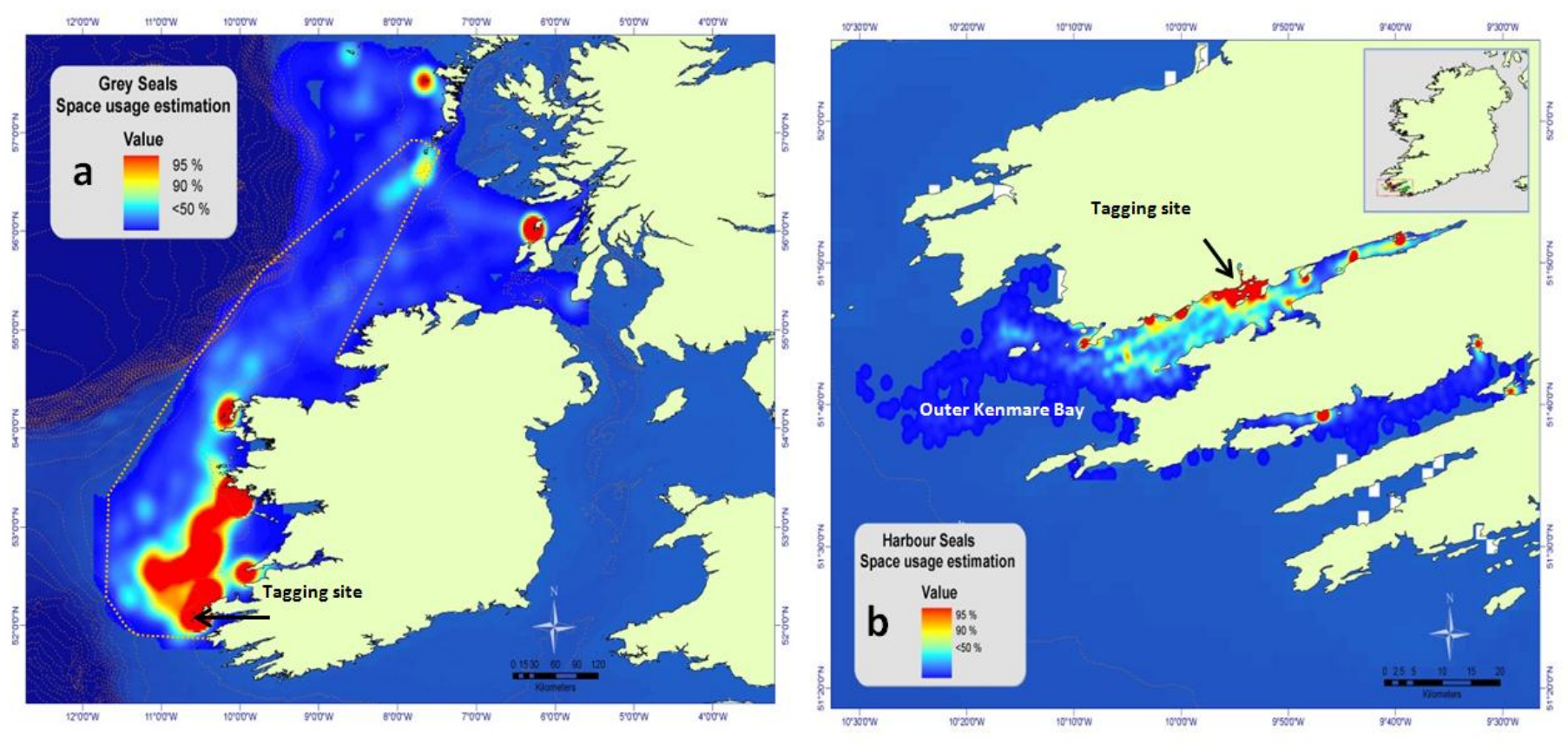

Figure 1 (a) Sampling area of grey seals on continental shelf (Feb-Dec 2009), tagging site at Blasket Islands, Co Kerry and outline of area compared to ocean model data shown (b) Sampling area of harbour seals in Kenmare Bay (April-August 2007 \& 2008), tagging site shown. 


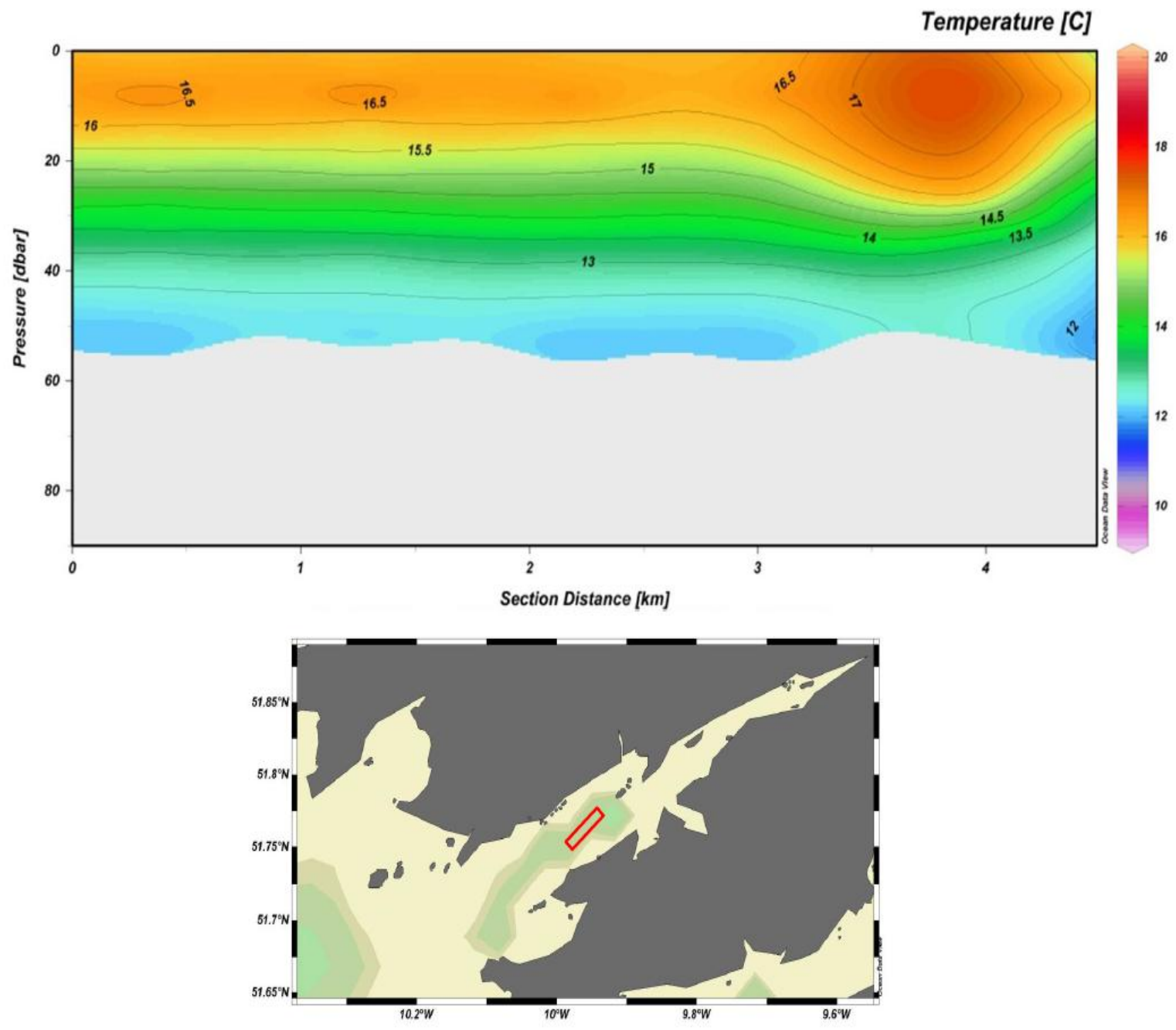

Figure 2. Summer water stratification in lower Kenmare Bay during August 2006. Cross section of bay represented is indicated on map. 

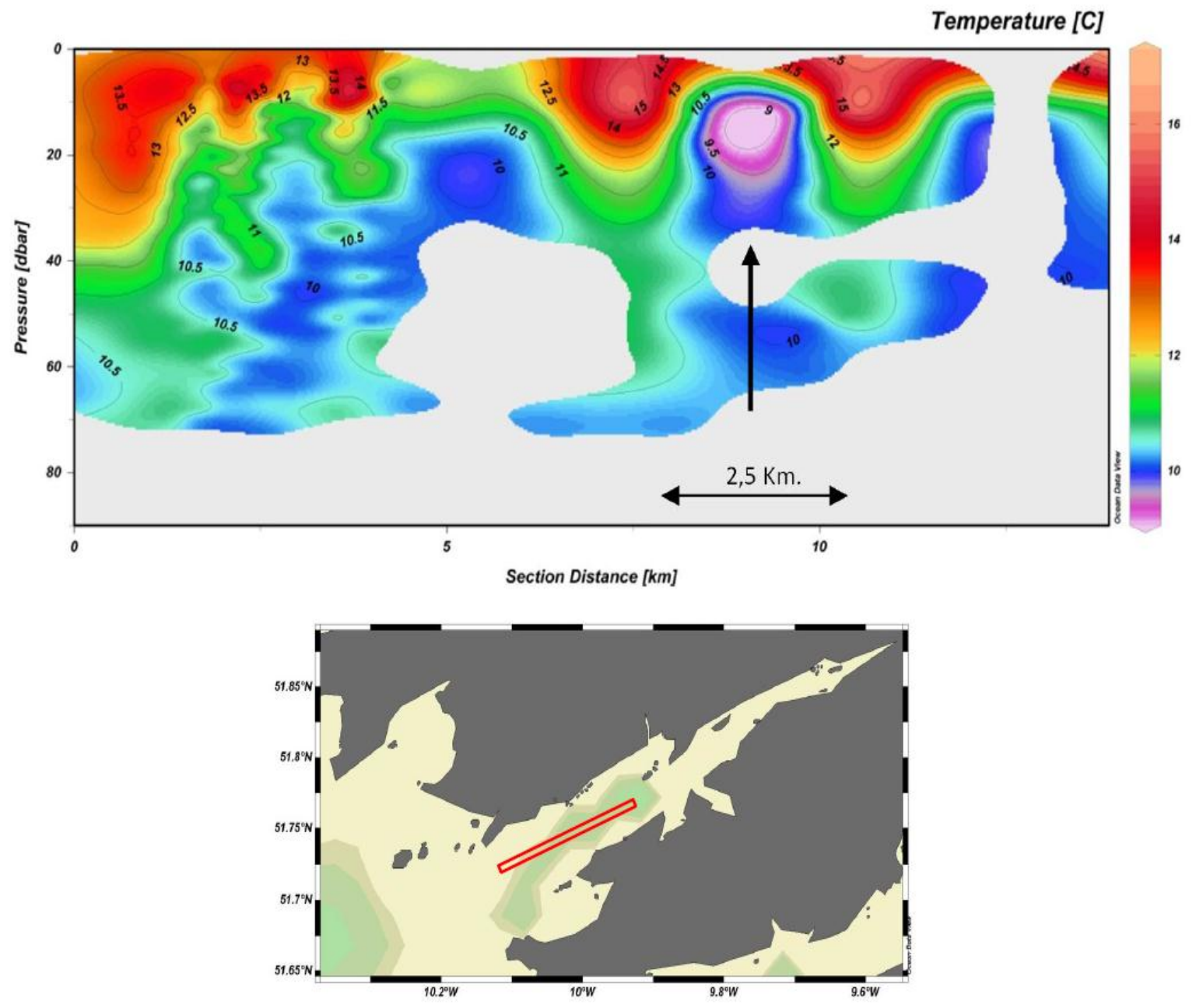

Figure 3. Evidences of transient local upwelling in the area of Kenmare Bay during June 2006. Cross section of bay represented is indicated on map. 

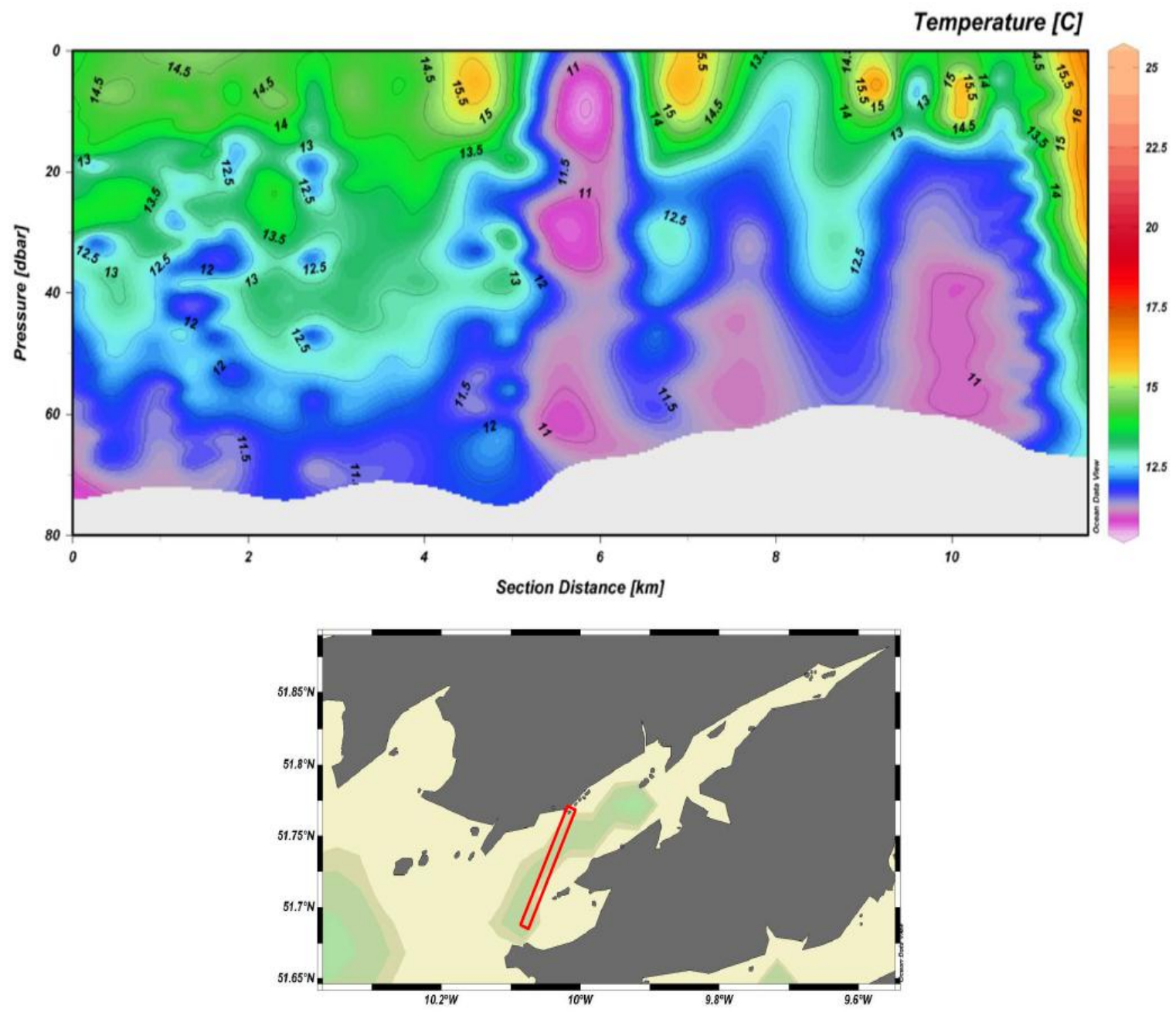

Figure 4. Evidences of local upwelling in the area of Kenmare Bay during June 2007. Cross section of bay represented is indicated on map. 
Temperature in Celsius

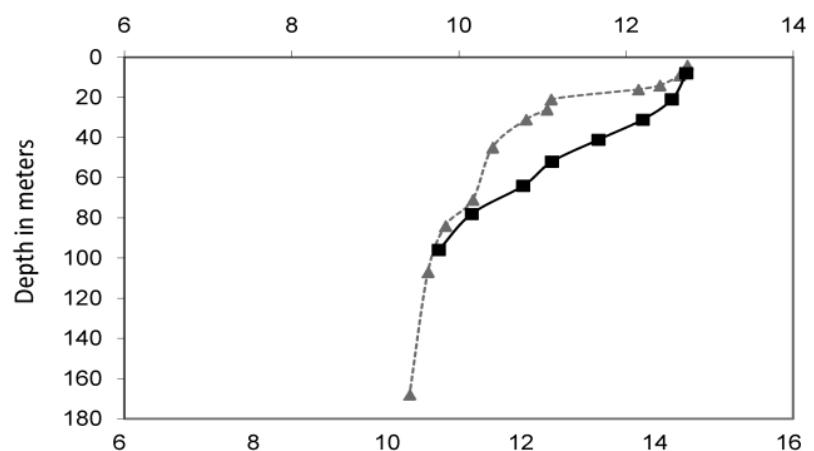

June 09

---1--- Seal data

- - Model predictions

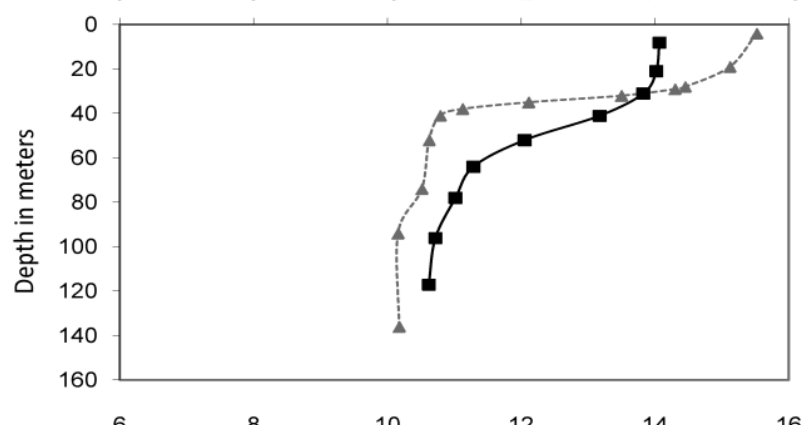

July 09

---1--- Seal data

$\longrightarrow$ Model predictions

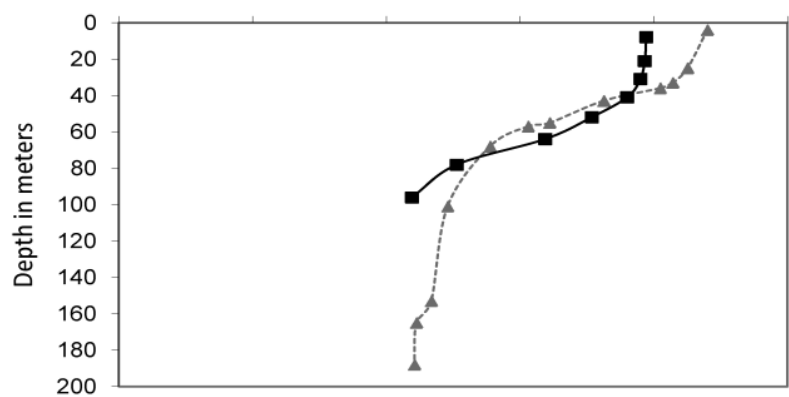

August 09

------ Seal data

$\longrightarrow$ Model predictions

Figure 5. Profiles of grey seal recorded and modelled water temperatures

(MPI-OM global ocean model) off west coast of Ireland during June-August 2009. 